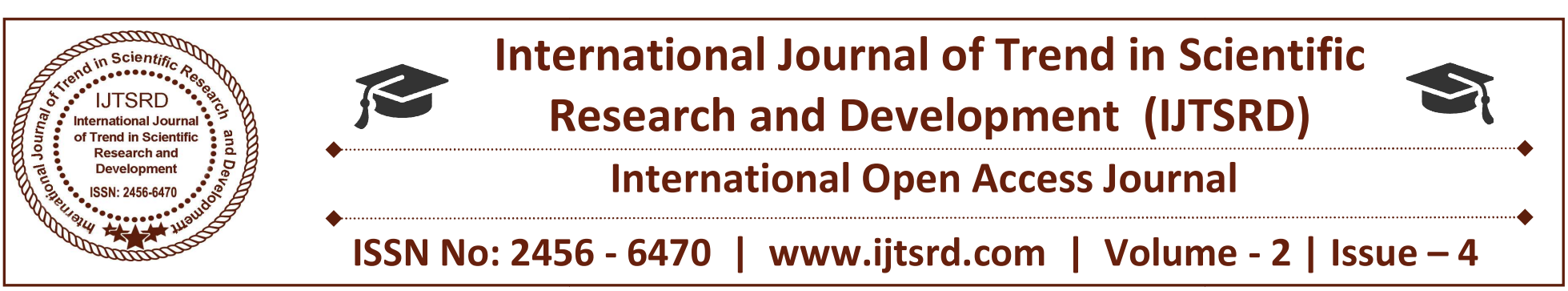

\title{
Significance of Phase Change Materials in Building Construction
}

\author{
Amena I. Tamboli ${ }^{1}$, Dhruv Rajpurohit ${ }^{2}$, Chinmay Jadhav ${ }^{2}$, \\ Arpit Gohokar ${ }^{2}$, Sadanand Nanote ${ }^{2}$, Subham Dhote ${ }^{2}$ \\ ${ }^{1}$ Assistant Professor, ${ }^{2}$ U.G. Student \\ Sinhgad Academy of Engineering, Pune, Maharashtra, India
}

\begin{abstract}
:
Buildings are designed for the sole purpose of maintaining conducive living standards for the occupants. Electrical energy consumption varies significantly during the day and night according to the demand by the industrial, commercial and residential activities. PCMs are regarded as a possible solution for reducing the energy consumption of buildings. These are the materials that could store a large amount of energy in the form of latent heat at a constant temperature without any fluctuations or variations in the temperature. Buildings which have large mass will react slowly to changes in heating and cooling demands. This research is done to study the temperature fluctuations at 3 different layers of the model walls (outer face, inner face, intermediate face) throughout the day. The fluctuation of temperature taking 3 different PCMs viz. HS29, HS24 and HS34 are studied. For temperature readings, Arduino Nano processor is used with LM35 temperature sensors connected to the central IC.
\end{abstract}

Keywords: phase change materials, latent heat, PCM, green building, thermal insulation.

fluctuations or variations in the temperature. Phase change materials (PCMs) have low temperature range and high energy density of melting - solidification compared to the sensible heat storage. This property of the PCMs finds its usage in many fields of energy conservations to a greater extent.

\section{Principle of Phase Change Material:}

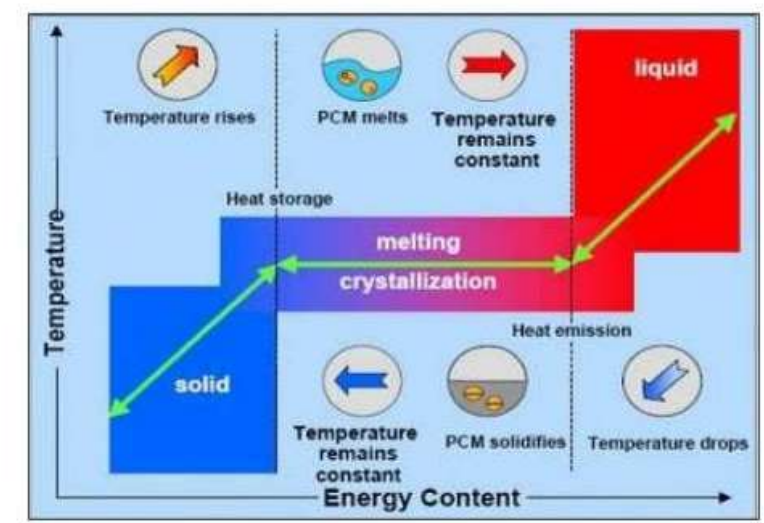

fig. 1: principle of PCMs

\section{INTRODUCTION}

In the world where there is a continuous increase in the emission of greenhouse gases into the atmosphere and increase in global temperature exponentially it is necessary to use technologies to find a way to reduce the temperature of the buildings inside. In hot and cold climate countries, the major part of the load variation is due to the air conditioning and space heating respectively. Buildings that will have large mass will react slowly to changes in heating and cooling demands. PCMs are the materials that could store a large amount of energy in the form of latent heat at a constant temperature without any 
International Journal of Trend in Scientific Research and Development (IJTSRD) ISSN: 2456-6470

Table 1. Classification of PCMs

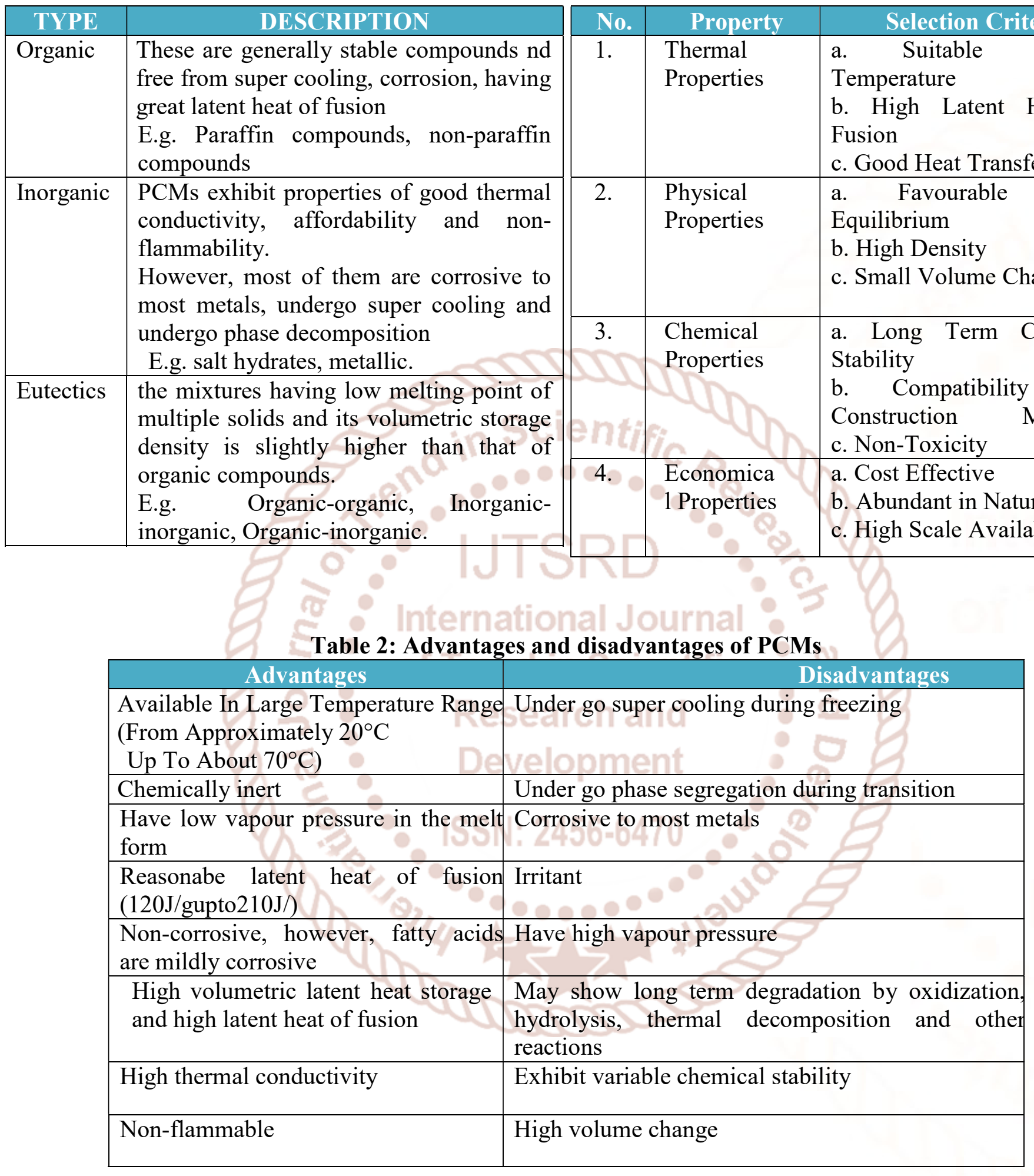

Table 2: Properties of PCMs

Melting
Heat of
Phase
eria
Chemical
with
Materials
re

\section{Objectives}

To reduce the energy consumption of buildings which can be considered in construction of sustainable and energy efficient buildings. To store thermal energy in building walls at peak temperature hours and use it at the low temperature hours.

\section{Experimental setup}

1. Materials and equipment specifications:

> Hollow concrete blocks of size $35 \times 20 \times 20 \mathrm{~cm}^{3}$ with two cavities each of $15 \times 15 \times 18 \mathrm{~cm}^{3}$

$>$ PCM packaging is done by small packets of polythene which are filled with $140 \mathrm{ml}$ of PCMs and then sealed by thermal sealing machine. 
$>$ The model size is $125 \times 125 \mathrm{~cm}^{2}$ which stands $66 \mathrm{~cm}$ in height. Sealed PCM packets are placed with sand in the cavities.

> Out of total 36 bricks, 9 are filled with HS24, HS29 and HS34 respectively. The remaining bricks are not filled with any material.

> A temperature sensing apparatus is built using Arduino Nano processor and 12 LM35 temperature sensors on IC CD4051.

Fig. 3: hollow concrete block filled with PCM packet and crushed sand

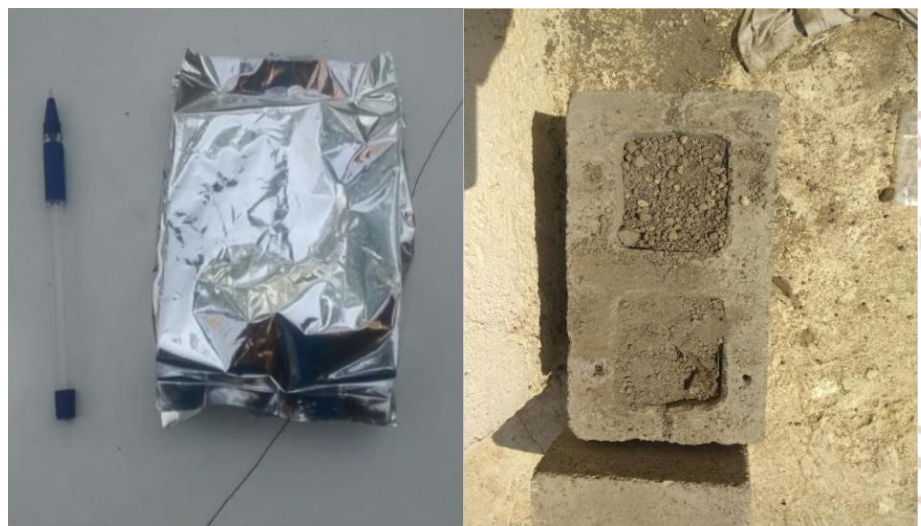

\section{Casting and curing:}

A small room like structure is constructed of size $125 \times 125 \times 66 \mathrm{~cm}$ The structure is casted on a movable steel trolley with 9 bricks on each side of structure. Structure is constructed of English bond with temperature sensors in three different lateral layers fitted in position. This structure is casted with keeping the side of wall with reference facing to north direction. These temperature sensors are fitted in between $2^{\text {nd }}$ and $3^{\text {rd }}$ vertical layer of bricks. The structure is casted and cured for 3 days

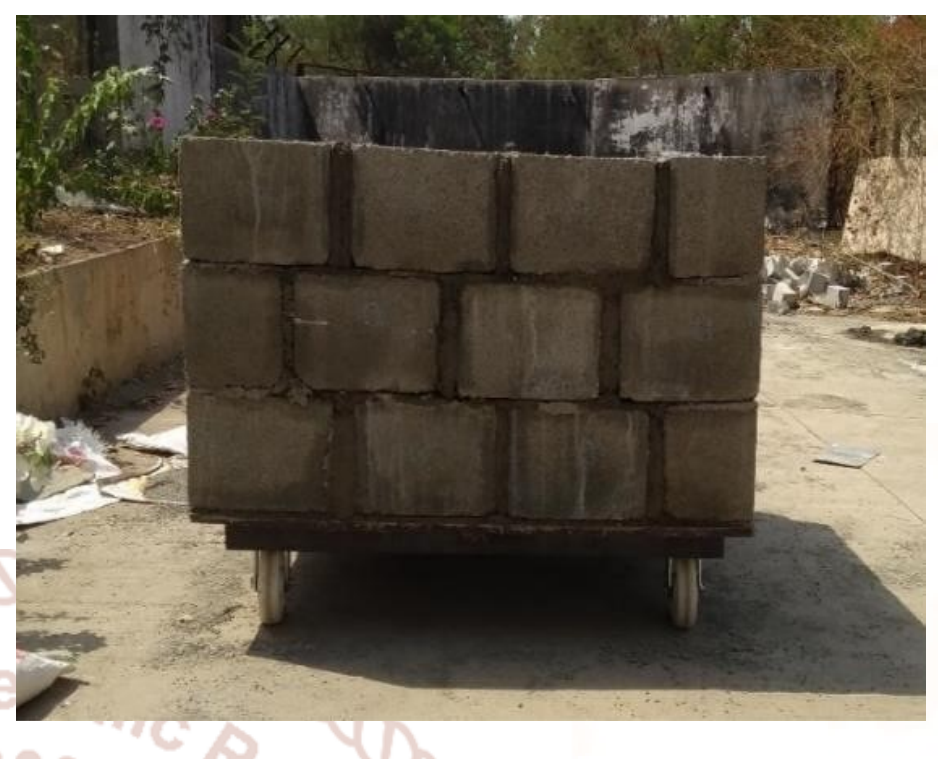

\section{Testing:}

The temperature readings of different layers for every half hour interval is recorded in the memory card installed on the central IC. The readings are taken from $28^{\text {st }}$ May 2018 to $30^{\text {th }}$ May 2018 (orientation 1). After this the readings are taken by rotating the model by $180^{\circ}$ from $3^{\text {rd }}$ June 2018 to $5^{\text {th }}$ June 2018 (orientation 2). Graphs of temperature versus time is plotted and shown below for $28^{\text {th }}-30^{\text {th }}$ may 2018 and $3^{\text {rd }}-5^{\text {th }}$ June 2018.

\section{Orientation 1}

WALL 1 HS 29

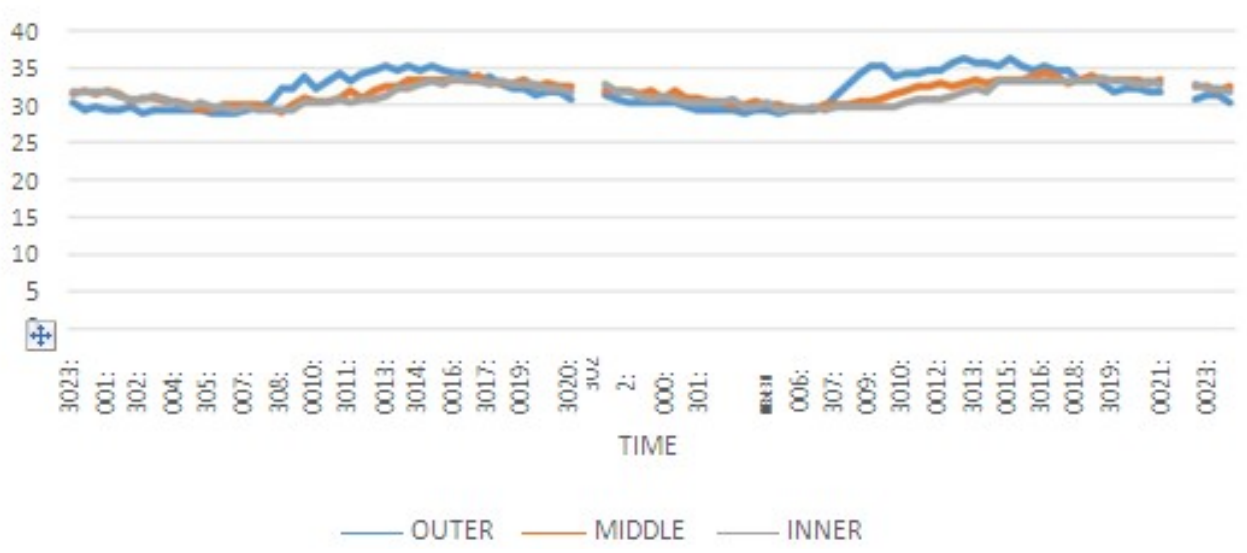


WALL 2 HS 24

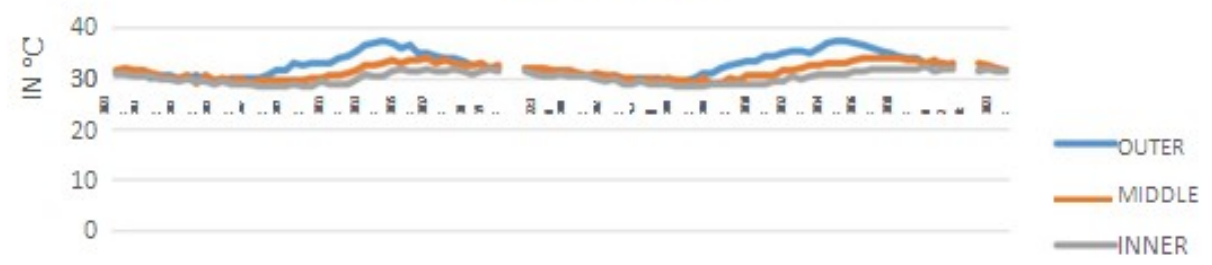

TIME

\section{WALL 3 REFERENCE}

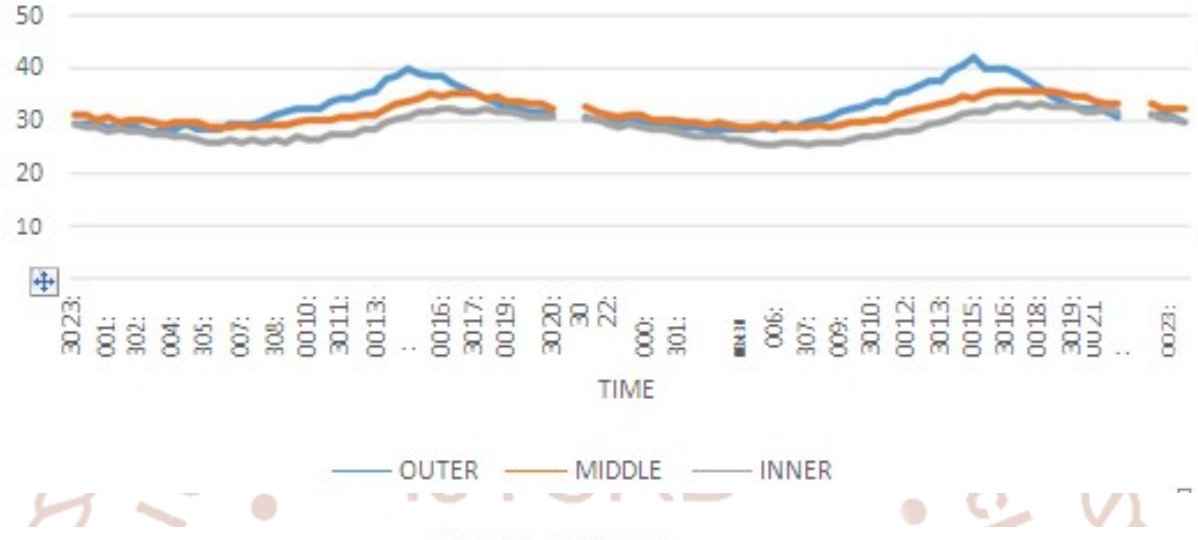

WALL 4 HS34
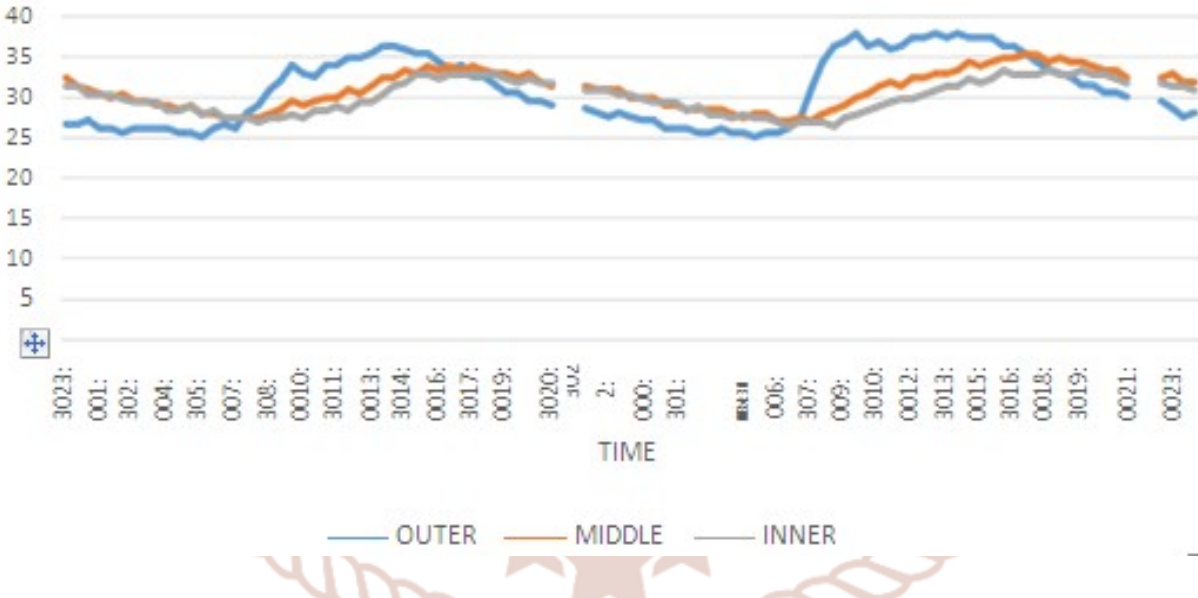

Orientation 2

WALL 1 HS 29

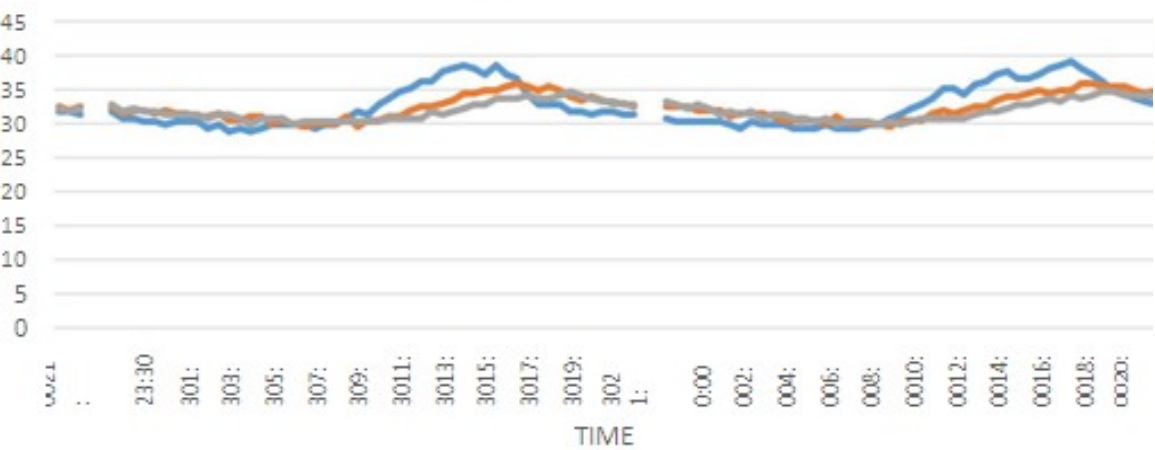

$\longrightarrow$ OUTER $\longrightarrow$ MIDDLE $\longrightarrow$ INNER 
WALL 2 HS 24

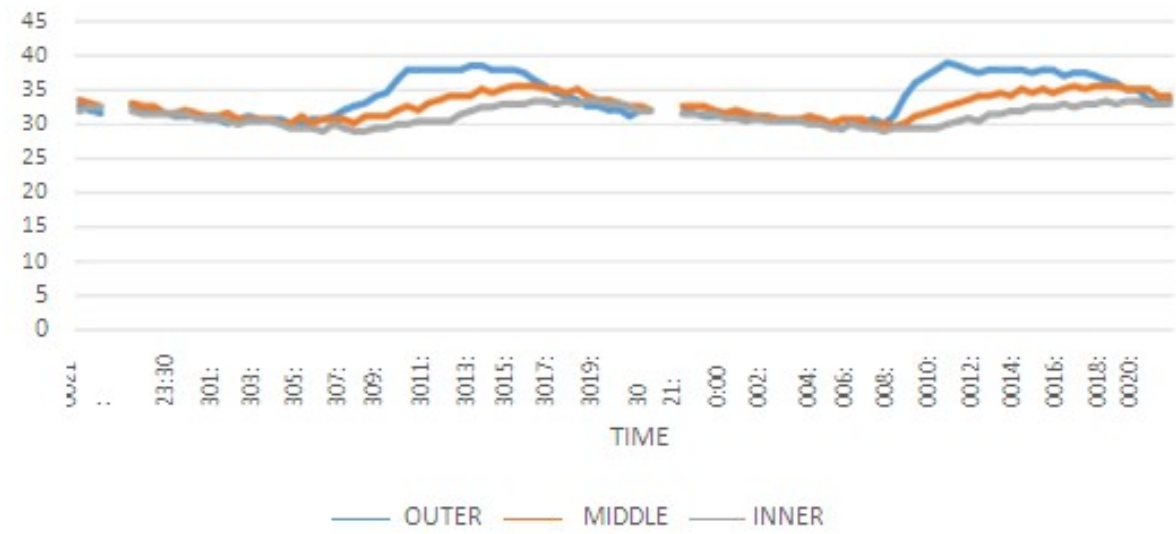

WALL 3 REFERENCE

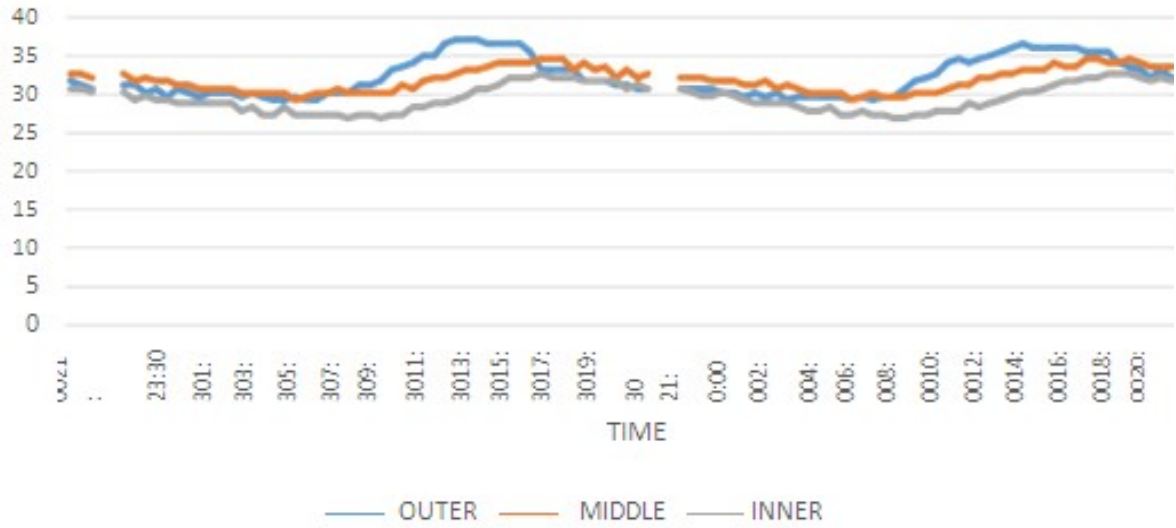

WALL 4 HS 34

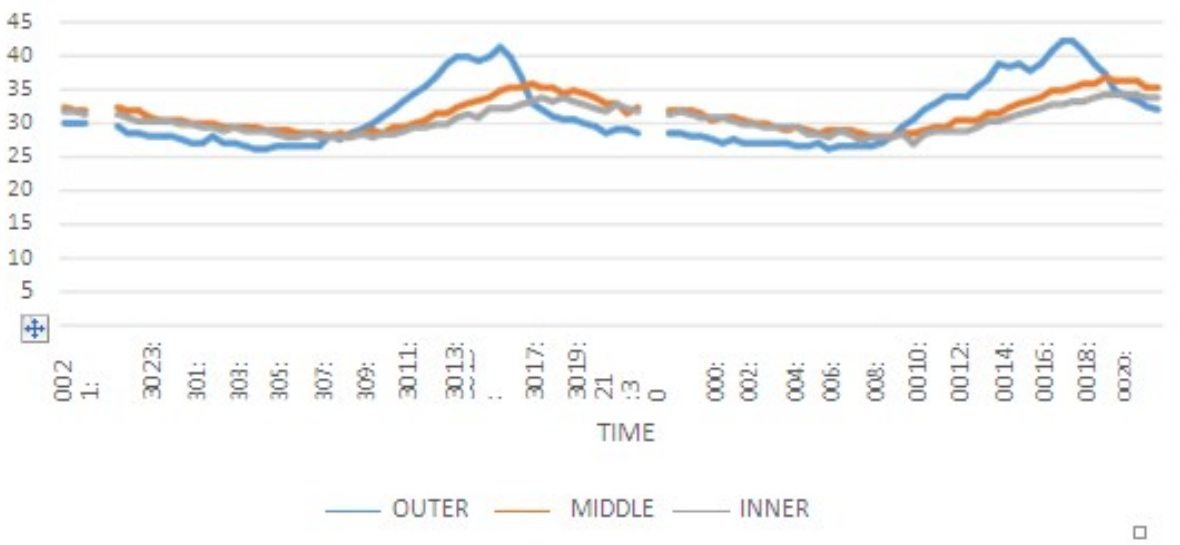

In orientation 1 (28 ${ }^{\text {th }}$ May 2018 to $30^{\text {th }}$ May 2018), Wall 4 (HS34) shows insulating properties, which shows a temperature difference of $6^{\circ} \mathrm{C}$ at peak hours with respect to Wall 3 (REFERENCE).

In orientation $2\left(3^{\text {rd }}\right.$ June 2018 to $5^{\text {th }}$ June 2018$)$, Wall 4 (HS34) shows insulating properties, which shows a temperature difference of $4^{\circ} \mathrm{C}$ at peak hours with respect to Wall 3 (REFERENCE). But here reference wall is restricted from direct sunlight exposure.

\section{Future scopes:}

For finding the effectiveness of PCMs the model should be tested in different weather conditions. Encapsulation method of PCM can be improved to increase the contact area. Expected life of PCMs is 10 years so further research on PCMs can help in increasing the life cycle of PCMs. Further research can be done for developing concrete friendly PCMs. Strength analysis can be done. Effects of combination of two or more PCMs can be studied. 


\section{Conclusions:}

After the study of temperature fluctuations in the walls we can thereby conclude that, the orientation of structure and direct exposure to sunlight are important factors while evaluating the effectiveness of PCM. The melting range of PCM need to be decided considering the local temperature conditions. The above experimental study shows a temperature drop of $5-6^{\circ} \mathrm{C}$ in orientation 1 , and $4-5^{\circ} \mathrm{C}$ in orientation 2 . Due to ambient weather conditions and cloudy weather, the results are quantitatively less effective than predicted.

\section{REFERENCES}

1. Sman Kumar Jha, Dr. S. Nallusamy and N. ManikandaPrabu (2015), "Study and analysis of thermal energy storage system using phase change materials (PCM)",. International journal of applied engineering research. ISSN 09734562 vol. 10 number 62 (2015)

2. L. Vankatesh, J. Amruth and Sambasiva Rao Sammeta (2014), "Phase Change Materials in building construction to reduce room temperature fluctuations", Internaional journal of mechanical and production engineering ISSN:2320-2092 vol. 2 issue 7 july 2014

3. M. Ravikumar and Dr. Pss. Srinivasan (2008), "Phase change material as a thermal energy storage material for cooling of building", Journal of theoretical and applied information technology 2005-2008 JATIT

4. Pawan R. Ingole, Tushar R. mohod and Sagargaddamwar (2014), "Use of phase change materials in construction of buildngs; A review", International journal of engineering research and general science ISSN 2091-2730 vol. 2 issue 4, june-july 2014

5. A. Abhat (university of Stuttgart) (1982), "Low temperature latent heat thermal energy storage:
Heat storage materials", Solar energy volume 30, no. 4, pp313-332.

6. F. Kuznik, D. David, K. Johannes and J-J Roux (2011), "A review on phase change materials integreated in building walls", Renewable and sustainable energy reviews, Elsevier, 2011, 15(1), pp.379-391.

7. Jan Kosny, "PCM enhanced building components", Short history of PCM applications in building envelopes (2015), Chapter1 and Chapter 2, Springer publications ISBN 978-3-54068556-2

8. Jan Kosny, Nitin Shukla and Ali fallahi (2013), "Cost analysis of simple PCM enhanced building envelopes in southern US climates". US department of energy (January 2013).

9. Shazim Ali Memon (2014), "Phase change materials integrated in building walls: A state of art review", Renewable and sustainable energy reviews 31(2014) 870-906.

10. CemilAlkan, Eva Gunther, Omer FarukEnsari and Deryakahraman (2012), "Polyurethanes as solidsolid phase change materials for thermal energy storage", Solar energy (23 may 2014) 86(2012) 1761-1769.

11. Jianqingchen, Donghui Yang, Jinghua Jiang, Aibin Ma and Dan Song (2014), "Research progress of PCM embedded with metal foam", Elsevier, Science Direct 4(2014) 389-394.

12. M. Kiviste and R. Lindberg (2014), "The feasibility of phase change materials in building structures for saving heating energy in the Nordic region", Agronomy research 12(3), 989-998 (2014)

13. Jan kosny, Jan kosny, David W Yarbrough and William A Miller, "Use of PCM enhanced insulation in the building envelope", Oak Ridge National Laboratory, Oak ridge, TN.

14. Advanced PCM market research, Global forecast to 2022. www.marketsandmarkets.com 